Article

\title{
Challenges and Driving Forces for Industry 4.0 Implementation
}

\author{
Iva Vuksanović Herceg ${ }^{1}$, Vukašin Kuč ${ }^{1}$, Veljko M. Mijušković ${ }^{1, *}$ and Tomislav Herceg ${ }^{2}$ \\ 1 Faculty of Economics, University of Belgrade, 11000 Belgrade, Serbia; iva.vuksanovic@ekof.bg.ac.rs (I.V.H.); \\ vukasin.kuc@ekof.bg.ac.rs (V.K.) \\ 2 Faculty of Economics and Business, University of Zagreb, 10000 Zagreb, Croatia; therceg@efzg.hr \\ * Correspondence: veljko.mijuskovic@ekof.bg.ac.rs; Tel.: +381-64-217-33-17
}

Received: 27 April 2020; Accepted: 17 May 2020; Published: 21 May 2020

\begin{abstract}
Industry 4.0 has been a major force framing the societal, economic and technological environment after 2010. Exposed to ongoing digital transformation, companies are able to exploit opportunities offered by Industry 4.0, and are forced to manage immanent risks and barriers. However, studies on opportunities and challenges relevant for the implementation of Industry 4.0 for companies are scarce. In response to this literature gap, the aim of this exploratory research is to provide a deeper analysis of the level of digital transformation of companies in Serbia based on a digital maturity model, and examine their managers' opinions on the most important driving forces and implementation barriers. The paper uses exploratory research design based on a survey responded to by 122 high-level managers within the Serbian manufacturing sector. Findings show that, contrary to expectations, digitally transforming enterprises do not see human resources as a driving force, but rather as an obstacle to Industry 4.0 implementation, when they lack necessary competences and skills. Resistance to change caused by Industry 4.0 implementation is not seen as an important barrier. On the other hand, efficiency factors represent the main driving force, while the lack of competences and financial resources represent the greatest barriers to Industry 4.0 implementation.
\end{abstract}

Keywords: industry 4.0; digital maturity; Serbian manufacturing sector; driving forces; barriers

\section{Introduction}

The Industry 4.0 has been one of the major forces framing the societal, economic and technological environment after 2010. Several other commonly known terms may point to the same phenomenon, such as the Industrial Internet, the Internet of (Every) Thing, the Big Shift, etc. In the context of global sustainable development (as defined by the UN Sustainable Development Goals), Industry 4.0 is expected to contribute in multiple areas, i.e., quantity of materials used, primary energy consumption, working conditions etc. [1]. On the business level, Industry 4.0 is expected to improve quality management processes. For example, the Foundry 4.0 stands for "an increase in automation in an effort to reduce defects" [2]. Furthermore, Industry 4.0 bears the potential for sustainable industrial value creation focusing on all three sustainability dimensions: economic, social and environmental [3].

In business management, Industry 4.0 is causing fundamental changes in existing business models and creation of new ones, known as the digital transformation [4]. With its ambivalent impact, disruption of incumbents and huge and vigorous opportunities for newcomers, the adoption of the Industry 4.0 (including Cyber Physical System, Cloud-based manufacturing, Internet of Things etc.) has become the source of competitive advantage for a company, as well as on the national level [5]. According to McDonald and Rowsell-Jones, Industry 4.0 bears the potential to completely reshape the relationships with customers, employees, the market etc. to create "a digital edge, where digital information and physical resources merge in new ways to create value and revenue" [6]. Moreover, 
digital transformation, or digitalization, is not limited to product and process improvement, affecting business models and organizational and management aspects as well as the entire supply chain, creating significant challenges for companies [7,8]. Lately, it has become clear that digital transformation should be reflected in innovation processes based on the Open Innovation principle $[9,10]$.

The Industry 4.0 was born in the production stage of the value chain merging physical production technologies with digital technologies [11]. There is a significant overlap between physical concepts embedded in manufacturing and the main breakthroughs of information and communication technologies. Robotics, sensors, artificial intelligence, augmented reality, business analytics and cognitive computing have gone mainstream. The result of these merges is digitalized and connected manufacturing [12]. However, the implications of Industry 4.0 for manufacturing companies are not unequivocal, since it promises higher efficiency and profitability as well as improved quality on the one hand, but it exposes companies to increased and often disruptive competition and difficult change management on the other hand [10]. Moreover, studies on opportunities and challenges that are considered relevant for the implementation of Industry 4.0 for companies are scarce [13-18]. As a consequence of unclear opportunities and challenges perceived by industrial manufacturers, evidence points to a slow and reluctant implementation of Industry 4.0 [19].

To account for ongoing change in business models towards digital transformation, recent literature established the concept of digital maturity [20]. The concept of maturity refers to a degree of completion or perfection of a desired transformation and thus can be applied to an organization's digital transformation [20] (p. 3). Maturity models can be seen as an instrument for measuring progress towards a specific target state [21,22]. Tarhan et al. provided a comprehensive literature review and showed that maturity models represent a "desired logical path which includes discrete levels of maturity" [23].

Apart from the maturity models, readiness models have been developed to test the readiness for initialization of the digitalization process. This analysis refers to the stages before the process of digital maturing and thus does not represent the area of interest of this research. Digital maturity has been generally seen as a level (or status) of digital transformation of the company [24] (p. 4). Additionally, it reflects the organization's adaptation to compete effectively in an increasingly digital environment [19]. In constructing digital maturity models, the main aspects of digital transformation have been included, namely, apart from physical products, digitalization affects business models, organizational structure and strategy [14,25]. Additionally, it should be based on consumer needs and preferences [26].

The roots to maturity models go back as far as the 1930s. Shewhart [27] first began to study process improvement. His principles were further refined by Deming [28], Crosby [29] and Juran [30] in the area of quality management.

Humphrey's [31] adaptation of Shewhart's findings in the digital sphere is referred to as the Capability Maturity Model (CMM). It goes without saying that this model provided basic principles and concepts on which many of today's maturity models are based [32]. For example, the European Foundation for Quality Management (EFQM) has defined the so-called EFQM Excellence Model [33] with five enabler criteria and four result criteria, where the enablers are underpinning the results. A majority of digital maturity models were developed in a practical context, by consulting firms, and test the company's digital transformation from a holistic perspective. Namely, management consultancies bear broad knowledge on digital transformation management [34]. For example, PricewaterhouseCoopers [35] developed a six-dimension maturity model that detects four levels of digital maturity: digital novice, vertical integrator, horizontal integrator and digital champion. Other consulting firms, like KPMG, McKinsey and Company, Accenture etc., have also developed their own models for measuring digital maturity. Most of the maturity models and especially those developed in management consultancy are not empirically grounded. However, Deloitte provided empirical research prior to developing its digital maturity model [35]. This model is used to evaluate digital capability across five dimensions to create a holistic view of the organization's digital maturity [36]. 
The core dimensions (Customer, Strategy, Technology, Operations, Organization and Culture) are divided into 28 subcategories and 179 criteria based on which digital maturity is assessed. The similar maturity model is developed and discussed extensively in Schumacher et al. [22], although with nine dimensions.

The MIT Center for Digital Business and Capgemini Consulting developed a model that evaluates digital maturity across two dimensions and assigns one of four maturity levels: beginners, fashionistas, conservatives and digiratis [37]. Similarly, the Institute for Information Systems at the University of St. Gallen in cooperation with the Swiss management firm crosswalk developed a nine-dimension digital maturity model based on 60 different indicators of digital transformation that classifies companies into five linear digital maturity stages [38,39].

Lichtblau et al. [40] developed a one-dimensional model with six maturity stages that differentiate among three digital maturity types: newbies, beginners, and pioneers. Schumacher et al. [12] proposed a nine-dimension maturity model for assessing Industry 4.0 readiness and digital maturity of enterprises that extends the dominating technology focus by including organizational aspects (Strategy, Leadership, Governance, Culture and People). Lanza et al. [41] offered a "maturity-based action guide" without developing a specific measurement model.

According to Savastano et al. [42] (p. 893), "despite the increasing interest in this novel topic, scholarly inquiry on the economic and managerial effects of the digital transformation of manufacturing as well as its impact on business models' innovation has transpired in the literature only recently, resulting in a limited understanding of this phenomenon". So far, there has been no research of the digital maturity of companies in Serbia. Furthermore, there is practically no scientific literature on digital maturity based on empirical research [20].

Motivated by the mentioned research gap in the literature, this paper has two objectives. Firstly, to examine the progress in implementation of Industry 4.0 in manufacturing companies in Serbia. The paper explores the digital maturity stage of the companies, based on the Deloitte Digital Maturity Model. Secondly, to identify the main opportunities and challenges (barriers) for Industry 4.0 adoption in Serbia based on higher-level manager's opinions from digitally matured companies.

This paper makes several potential contributions to the present body of knowledge. Firstly, it can provide evidence of the relative importance of the most important driving forces and barriers of the Industry 4.0 implementation. Secondly, it provides an insight into the sustainability of the Industry 4.0 implementation process since it investigates the main limitations to this process as perceived by the manufacturing companies' managers. Finally, it provides an insight into a specific country case, which can be used as a benchmark for other Central and Eastern Europe as well as Southeastern Europe countries.

Following the aims of the research, the paper is structured as follows. In Section 2 ("Methods") the research design is described, along with the methodology and the developed hypotheses. The main empirical results are displayed in Section 3 ("Results"). In Section 4 ("Discussion") findings are discussed, as well as theoretical and practical implications of the research. Finally, Section 5 ("Conclusions") brings the conclusions concerning the main findings, limitations and traces the future research paths.

\section{Methods}

The aim of this research is to provide a deeper analysis of the level of digital transformation of the manufacturing enterprises in Serbia and examine their managers' opinions on the most important driving forces and implementation barriers. Since a study is performed concerning the problem that is rather at its preliminary stage (especially in Serbia) without much empirical evidence in the background, an exploratory research design is applied [20].

At the beginning of the research the authors developed the hypotheses that are tested within the following study. The hypotheses are based on the relevant literature on Industry 4.0 characteristics and implications. 
- Hypothesis $\mathbf{1}\left(\mathbf{H}_{\mathbf{1}}\right)$. Human-related factors represent a significant driving force and a challenge for the Industry 4.0 companies;

- Hypothesis $\mathbf{2}\left(\mathbf{H}_{\mathbf{2}}\right)$. Achieving a competitive advantage is a major driver of Industry 4.0;

- Hypothesis $\mathbf{3}\left(\mathbf{H}_{3}\right)$. High costs of financing represent a major barrier to Industry 4.0 implementation in Serbia;

- Hypothesis $4\left(\mathbf{H}_{4}\right)$. Resistance to change creates pressure against Industry 4.0 implementation.

Given the exploratory nature of the research, after analyzing the available literature on the most important challenges and opportunities of the Industry 4.0 and digital maturity models, the authors have developed the survey amongst managers of Serbian companies, which was hosted and supported by the Serbian Chamber of Commerce. The chosen research design allowed for the investigation of precise Industry 4.0 issues from the managerial perspective as well as extending the existing state of research. The sample was carefully chosen in order to gain insight into the most important driving forces and barriers for Industry 4.0 based on experience gained in the companies that are likely to be exposed to digital transformation. According to Kagermann et al. [11], manufacturing sub-sectors, such as mechanical and plant engineering, the automotive industry and the electrical industry would be primarily affected by Industry 4.0. Consequently, the manufacturing sector was the focus of the research. The authors used a non-random approach for data collection, which is common in survey-based studies when respondents must be familiar with the studied phenomenon in order to increase the representativeness of the collected data [43,44]. Our selection criteria were that participants should be members of the top management team in manufacturing sector companies. The survey was open for 45 days (beginning from 1 April 2019), and responses were collected online (using Google form-a free online survey) as well as in paper form. In total, 123 responses were collected, out of which 122 were useful, which represents a $78 \%$ response rate, and approximately $5.5 \%$ of the total number of companies that fulfill the predefined qualifications.

The research variables are in connection with both the companies and the individuals. The former are described by their name, the industry in which their largest revenue is generated, their best-selling product/product line, year of establishment, number of employees and relative innovativeness. The minimum age of the companies eligible for the survey was set to be 5 years, and the minimum number of employees was set to be 10 . Individuals are described by the following variables: the respondents' gender, functional background, work experience in years, role at the company, how long they have been working for that company and how long they have been working in that role at the company.

The questionnaire consisted of two parts. The first part referred to obtaining information about the interviewee and the company. The second part was related to the Industry 4.0 and consisted of the following sections:

1. Industry 4.0 interpretation, driving forces and barriers;

2. Industry 4.0 maturity;

3. Industry 4.0 national technological platform.

The first part was based on the most frequently mentioned driving forces and challenges or barriers in the literature. Regarding the driving forces, several areas of Industry 4.0 impact were identified: competitiveness and business model [5,45-51]; efficiency and performance [3,34,45,52-58]; workforce-related factors [57-61]; and consumer needs [26,62]. Likewise, the most important barriers refer to: implementation efforts and costs $[45,58,60,63]$; organizational challenges $[16,47,54,60]$; and human capital (competences and resistance) [60,64-66]. Table 1 summarizes the main driving forces and barriers found in the literature. 
Table 1. Driving forces and barriers for Industry 4.0 implementation.

\begin{tabular}{|c|c|}
\hline Driving Forces & Sources \\
\hline Competitiveness and business model innovation & $\begin{array}{l}\text { Lasi et al. [5]; Rüßmann et al. [45]; } \\
\text { Burmeister et al. [46]; Arnold et al. [47]; Laudien and } \\
\text { Daxböck [48]; Laudien et al. [49]; Ibarra et al. [50]; } \\
\text { Ślusarczyk [51]. }\end{array}$ \\
\hline Cost reduction and performance improvement & $\begin{array}{c}\text { Rogers et al. [52]; Rogers and Trombley [53]; } \\
\text { Brettel et al. [54]; Geissbauer et al. [34]; } \\
\text { Schmidt et al. [55]; Rüßmann et al. [45]; Erol et al. [56]; } \\
\text { Stock and Seliger [3]; Oettmeier and Hofmann [57]; } \\
\text { Müller et al. [58]. }\end{array}$ \\
\hline Labor market changes & $\begin{array}{c}\text { Bonekamp and Sure [59]; Kiel et al. [60]; Oettmeier and } \\
\text { Hofmann [57]; Müller et al. [58]; Agolla [61]. }\end{array}$ \\
\hline Customer needs & Spath et al. [62]; Seufert and Meier [26]. \\
\hline Barriers & Sources \\
\hline Financial issues & $\begin{array}{l}\text { Herrmann et al. [63]; Rüßmann et al. [45]; } \\
\text { Kiel et al. [60]; Müller et al. [58]. }\end{array}$ \\
\hline $\begin{array}{l}\text { Organizational challenges (planning system, } \\
\text { protocols, coordination) }\end{array}$ & $\begin{array}{l}\text { Brettel et al. [54]; Arnold et al. [47]; } \\
\text { Kiel et al. [60]; Basl [16]. }\end{array}$ \\
\hline Managers' and employees' competences & Erol et al. [65]; Kiel et al. [60]; Basl [16]. \\
\hline Resistance & Bauer et al. [64]; Kiel et al. [60]; Nagy et al. [66]. \\
\hline
\end{tabular}

In examining the relative importance of Industry 4.0 driving forces and the main barriers, the authors used an unlabeled bipolar semantic differential scale [67] with seven points, where the middle point represents the indifference between the two factors. The second part was dedicated to the measurement of the digital maturity level of the sample companies. Deloitte's digital maturity model with five core dimensions (Customer, Strategy, Technology, Operations, Organization and Culture) was used due to its simplicity and empirical ground. In the third part, the authors explored the managers' opinions on the desired and lacking support by specific stakeholders engaged in their digital transformation.

To analyze the data, the research proceeded in three phases. Firstly, the level of digital maturity of the sample companies was identified, placing them in one of three groups: lower digital maturity, median digital maturity and higher digital maturity. Secondly, the data related to higher digital maturity companies and their manager's opinions were extracted and used to obtain the results about the main driving forces and barriers to Industry 4.0 implementation in Serbia. Finally, the authors examined the level of digital maturity of individual value chain activities in higher digital maturity companies. In general, maturity assessment is conducted by assessors [68]. However, maturity assessment can also be made by an external auditor or by self-assessment [69]. Furthermore, executives' self-assessment reports are commonly used in social sciences [70,71]. Accordingly, in order to identify the level of digital maturity, the managers were asked to imagine a perfect organization transformed by digital technologies across five given dimensions (Customer, Strategy, Technology, Operations, Organization and Culture). As the concept of maturity refers to a degree of completion or perfection of a desired transformation, the respondents were then asked to rate their company regarding the extent to which they perceived their organization's maturity level along each of the five dimensions on a scale of 0 to 100, where 100 represents an ideal state. Precisely, managers were asked to answer the following questions:

- Regarding your strategy, how advanced (matured) is your company to embrace digital initiatives in order to gain competitive advantage? 
- Regarding the technology in your company, does it enable the organization to create, process, store, secure and exchange data to meet the needs of customers and organizational processes at a low cost?

- Regarding the operations, do the processes and tasks utilize digital technologies to drive strategic management and enhance business efficiency and effectiveness?

- Regarding organization and culture, is decision making data-driven and are your employees digitally skilled?

- Regarding customer experience, do your customers view your organization as their digital partner using their preferred channels of interaction online and offline?

The average grades were used to place the sample companies into three groups created for the purpose of further analysis (see Figure 1): lower digital maturity (average grade $0-33 \%, 1 \%$ of respondents), median digital maturity (average grade $34-66 \%, 42 \%$ of respondents) and higher digital maturity (average grade $67-100 \%, 57 \%$ of respondents). As indicated by the creators of the model, it is used to extend the analysis and identify the gaps and key areas for the companies to focus on, in order to achieve full digital transformation [36]. Additionally, since the digital transformation represents a continuous process, and digital maturity is a moving target, given classifications are relative rather than absolute.

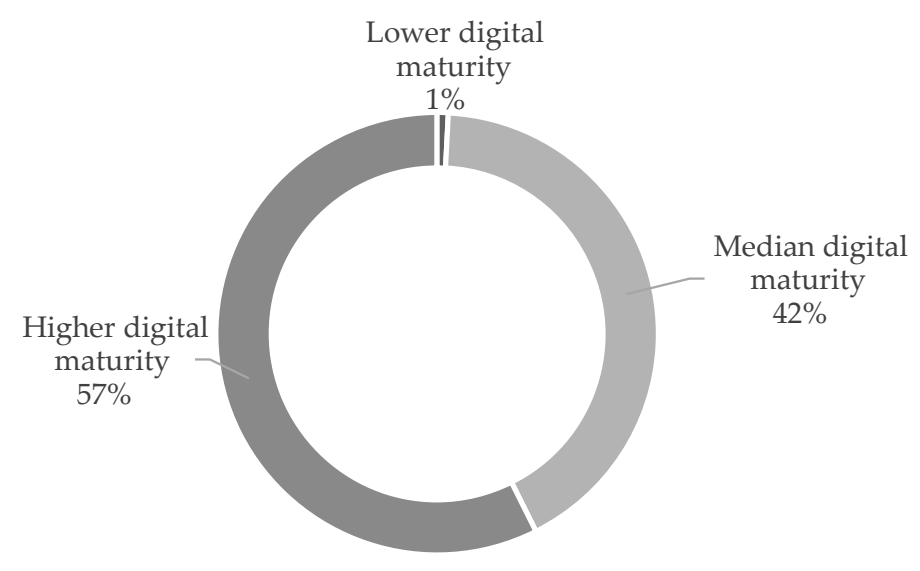

Figure 1. Digital maturity of the sample companies.

The sample was dominated by companies that have experienced and survived tremendous challenges as a result of the transition from Industry 2.0 to Industry 4.0. The average age of the observed enterprises was 27.4 years. Only $8 \%$ of companies were established in the Industry 4.0 era (after 2010). The general information about the sample companies is given within Table 2.

Table 2. General information about the sample companies.

\begin{tabular}{ccc}
\hline & Average & Median \\
\hline Number of employees & 173 & 92 \\
\hline Operating revenue (EUR) & $10,230,493$ & $4,247,884$ \\
\hline EBITDA margin (\%) & 11.8 & 9.9 \\
\hline Return on equity (\%) & 15.6 & 10.4 \\
\hline Age of the company (years) & 27.4 & 24.0 \\
\hline
\end{tabular}

According to the respondents, the companies in the sample are characterized by a relatively high degree of innovativeness. When asked to rate how innovative the company's products and offerings are (on a 0-100 scale) compared to the industry standard (50), the average grade of perceived 
innovativeness was 71.2 . The vast majority of managers $(74.8 \%)$ found their company's products and services more innovative than the industry standard, while the share of those who considered the company's offer to be at or below the industry standard was the same (12.6\% each).

Among the respondents, male respondents were more prevalent than female (64.8\% vs. $33.6 \%)$, while $1.6 \%$ preferred not to answer. The average work experience of the respondents was 20.6 years (see Figure 2). The respondents' extensive experience certainly contributed to the quality of this research. On average, they have worked 12.8 years in the observed companies. Most of them were founders or CEOs (32\%) while others worked in sales and marketing $(21 \%)$, production $(14 \%)$, product development (11\%), finance (11\%) and logistics (7\%).

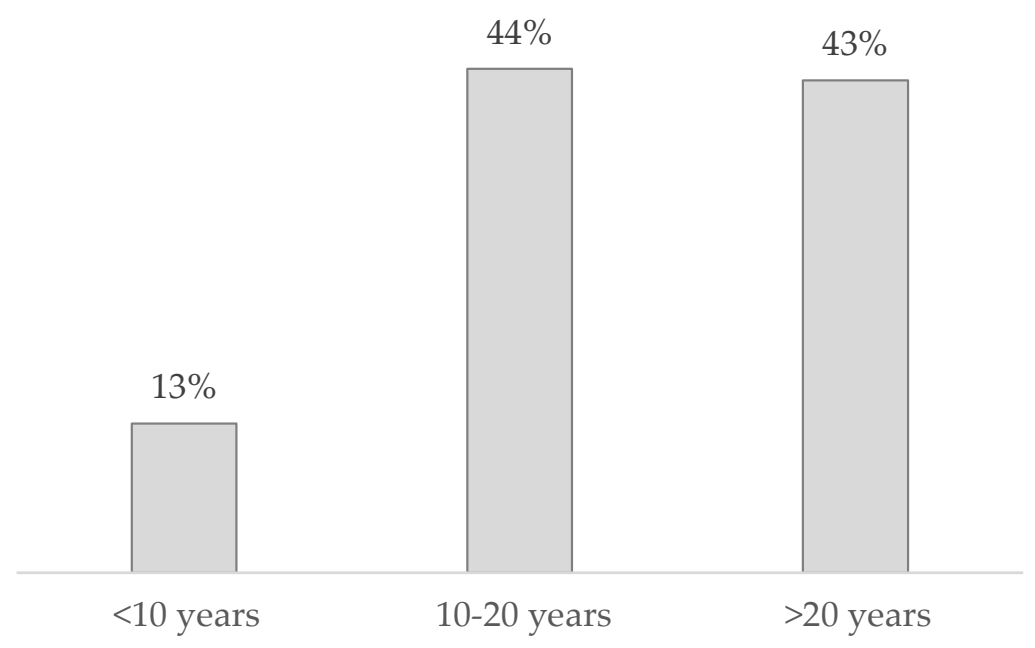

Figure 2. Work experience of the respondents.

Since different maturity level companies exhibit differences in the way they perceive the importance of various segments of business management (strategy, customer relationship, etc.) for digital transformation, the gaps in the maturity level across dimensions of the digital maturity model were analyzed within two segments (median and high digital maturity companies) (see Figure 3).

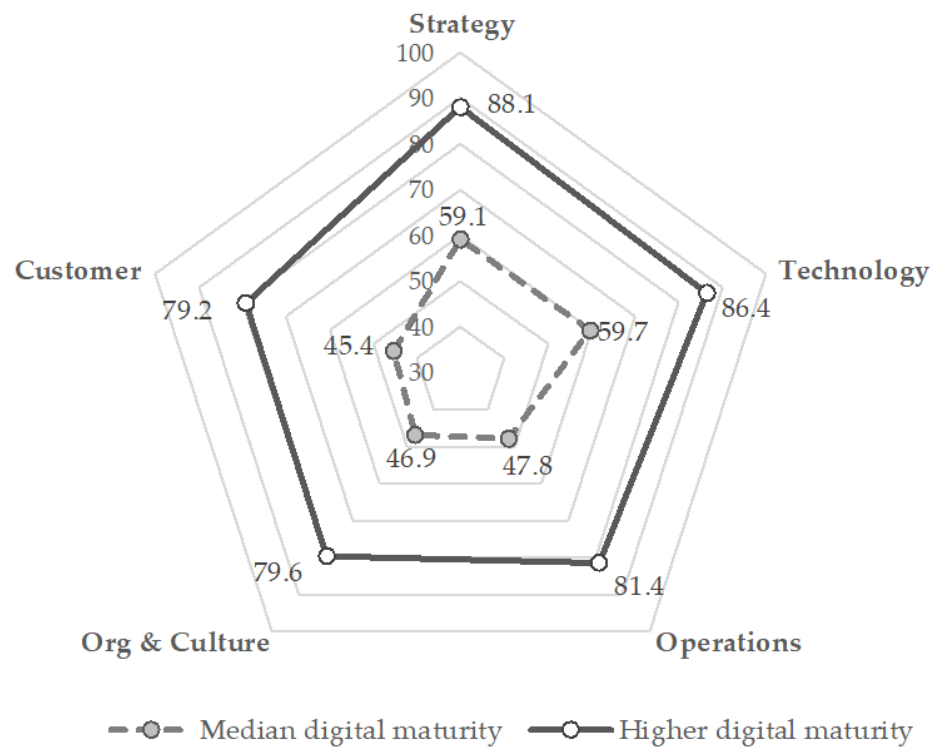

Figure 3. Digital maturity model — digital transformation across five dimensions (higher vs. median digital maturity companies). 
Consistent with other empirical studies, strategy is "the strongest differentiator of the digitally maturing companies" in comparison with the lower digital maturity level companies $[19,72,73]$. What separates the digital leaders in the sample from the others is a clear digital strategy combined with an organizational culture and leadership that drives transformation [72]. Digitalization is not about having digital technology, but rather about using it to change the current business model and create the new value-creating opportunities. This can only be achieved by aligning the company's strategy, technology, operations, organization and culture to meet the digital expectations of customers, employees and partners [19].

\section{Results}

\subsection{Industry 4.0 Driving Forces}

As mentioned in Section 2, in examining the relative importance of Industry 4.0 driving forces, the authors used an unlabeled bipolar semantic differential scale with seven points, where the middle point represents the indifference between two factors.

The results show that attempts to reduce costs represent a stronger driver of Industry 4.0 than the increasing labor shortage. This was the dominant attitude of the surveyed managers (53\%). The number of those who thought the opposite was nine times lower, while the indifferent ones made up $41 \%$ (see Figure 4a).

Similarly, the vast majority of respondents $(61.4 \%)$ considered market competition as a stronger driving force compared to the reduction of human work. A total of $14 \%$ of respondents had the opposite opinion, while the rest were indifferent (see Figure $4 \mathrm{~b}$ ).

The number of those who favored reducing the error rate compared to overcoming the challenges of the labor market (54.3\% of respondents) was 4.2 times higher than those who believed the opposite, while one third were indifferent (see Figure 4c).

According to the respondents, Industry 4.0 is predominantly a consequence of customers' or partners' demands and requirements compared to employees' requirements (51.5\% of respondents). The previous statement was made by 7.3 times more respondents compared to those who claimed the opposite (see Figure 4d).

Interestingly, financial drivers were not seen as dominant for Industry 4.0 implementation. For example, customer satisfaction was undoubtedly a more significant driver of Industry 4.0 than enterprise profitability. More than half of the respondents believed that improving consumer satisfaction is a more important driving force compared to an increase of return on assets $(51.4 \%)$, $27.1 \%$ of respondents gave equal importance, while $21.4 \%$ believed the opposite (Figure $4 \mathrm{e}$ ).

On the other hand, opposite to our expectation, building competitive advantage and overcoming competition were not seen as relatively more important in comparison to the internal drivers (Figure 4f,g).

As expected, the need for efficiency improvement was one of the most significant drivers of Industry 4.0. However, the study showed an unexpectedly high disproportion: more than half of the respondents $(52.9 \%)$ pointed out that improving efficiency is a more significant driving force than overcoming competitors, while those who thought the opposite were six times fewer.

Flexibility improvement represented a significant driving force behind compliance with managerial expectations, according to $48.6 \%$ of managers surveyed (Figure $4 \mathrm{~h}$ ). This is three times more than those who found compliance with managerial expectations to be a more important factor $(15.7 \%)$.

The results of this study also indicate that indifference exists when it comes to the following factors (drivers) of Industry 4.0: reducing expenditures vs. improving lead time ( $40 \%$ of respondents), improving market position vs. demand for quality improvement $(45.7 \%)$, ensuring full control of corporate processes vs. ensuring reliable operation (51.4\%) and compliance with customer needs vs. less stoppages in production (48.6\%) (for additionally mentioned drivers see Appendix A). 


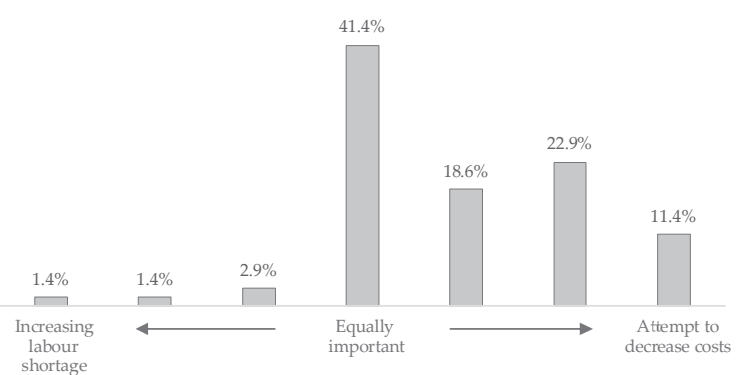

a)

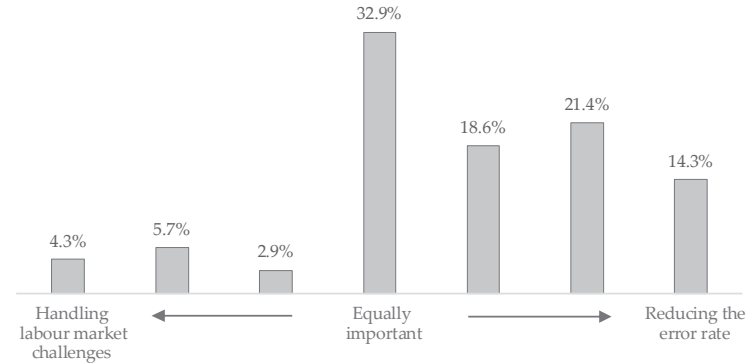

c)

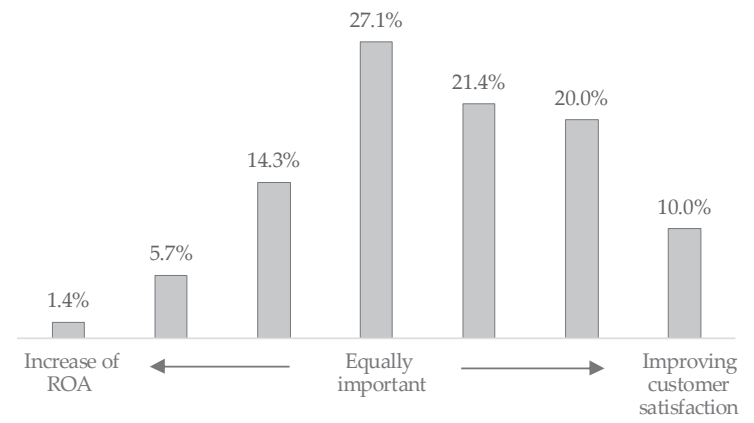

e)

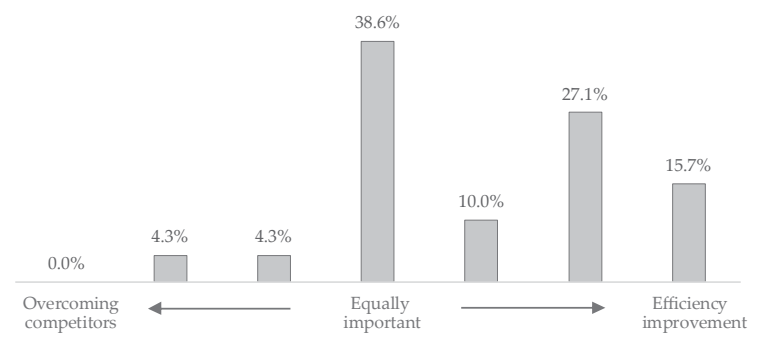

g)

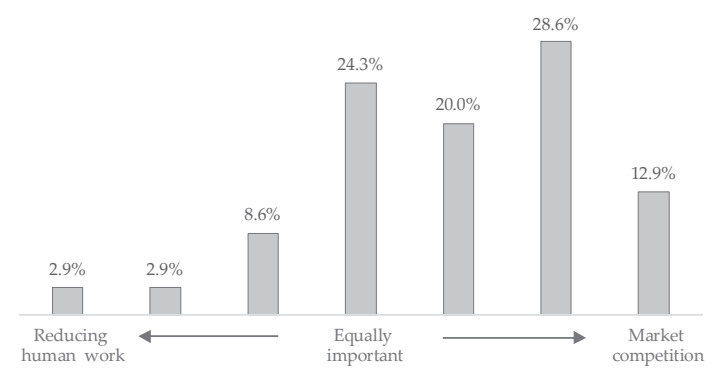

b)

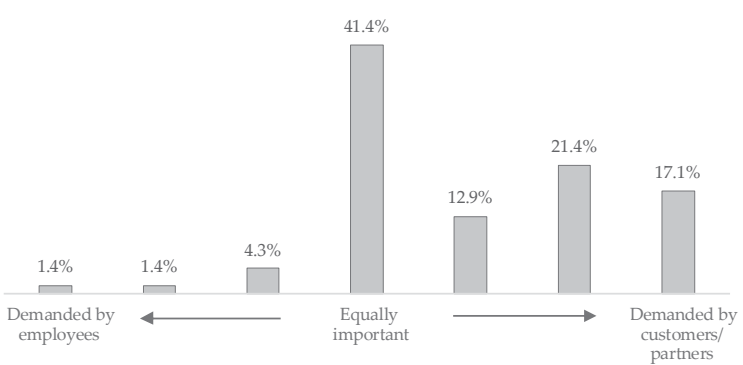

d)

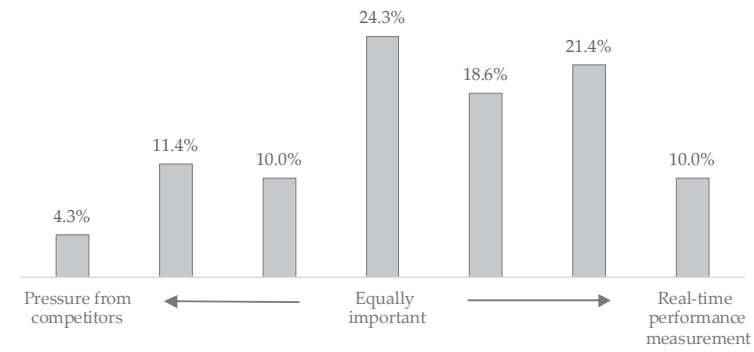

f)

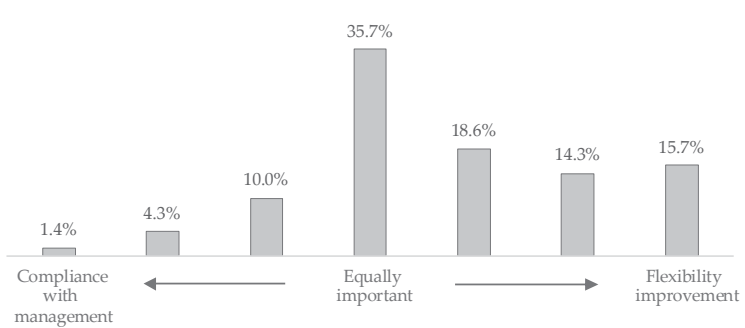

h)

Figure 4. Industry 4.0 driving forces. 


\subsection{Industry 4.0 Barriers}

When asked to prioritize between a lack of competencies and a lack of financial resources as barriers to Industry 4.0 implementation, $37.1 \%$ of managers considered a lack of competencies as a greater barrier, $34.3 \%$ were indifferent, and $28.3 \%$ thought that a lack of financial resources is a bigger issue (Figure 5a).

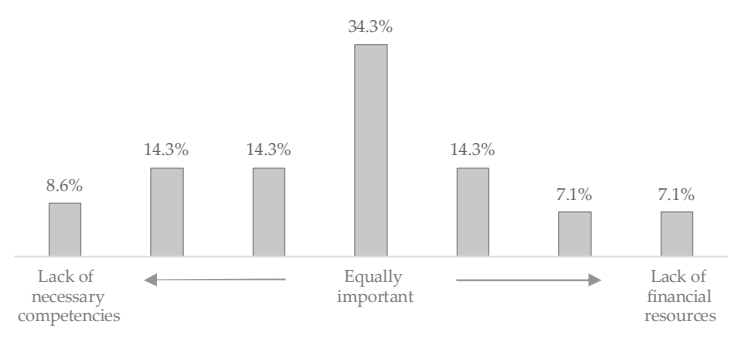

a)

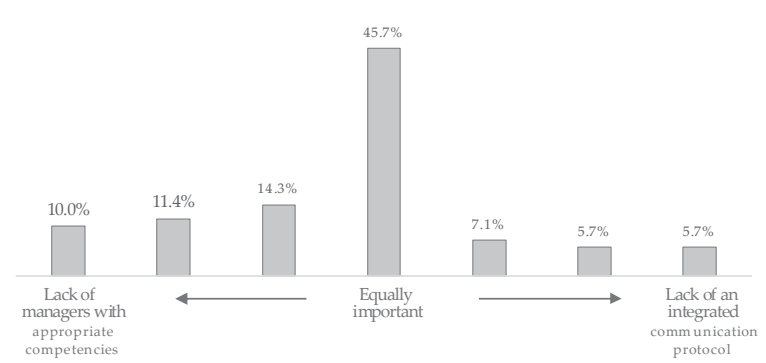

c)

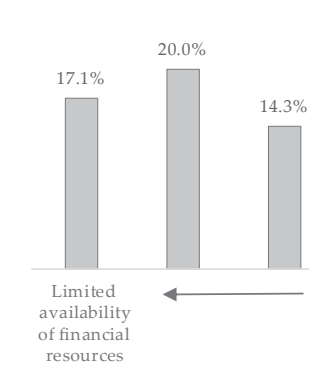

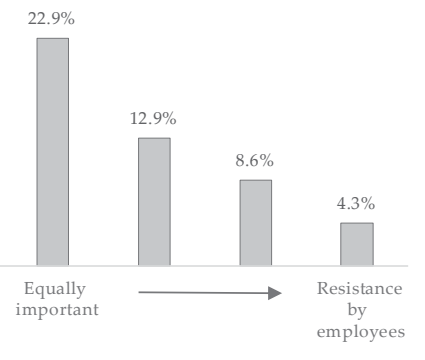

e)

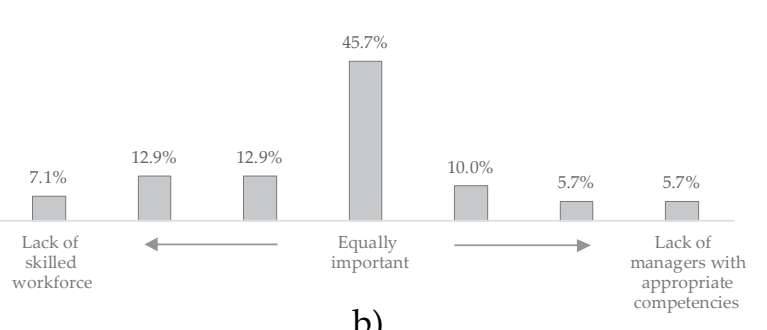

b)

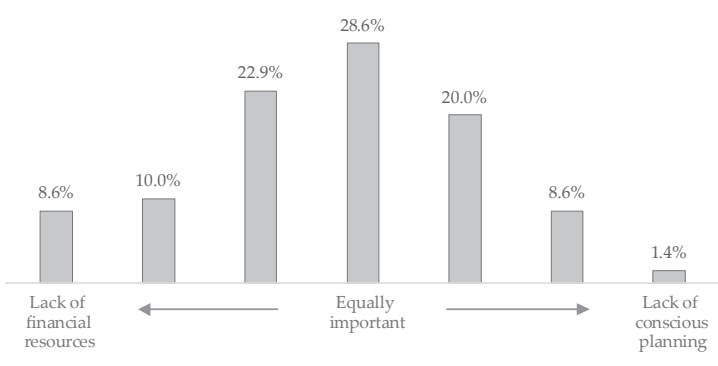

d)

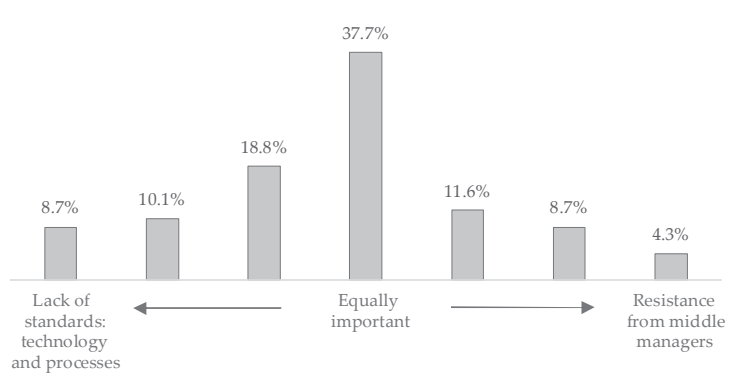

f)

Figure 5. Industry 4.0 barriers.

Furthermore, the study indicates that a lack of competencies is an equal problem at the managerial and lower hierarchical levels. The sample was dominated by those who give equal importance to the lack of a trained workforce and the lack of managers with appropriate competencies (45.7\%). However, it should be noted that the number of those who thought that the lack of a trained workforce is a significant barrier is $56 \%$ higher than those who thought that managerial competences represent a relatively bigger barrier (Figure $5 b$ ). 
Similar to the previous situation, the study indicates that a lack of integrated communication protocol is also a problem at the managerial and lower hierarchical levels. The sample was dominated by those who gave equal importance to the lack of an integrated communication protocol and the lack of managers with appropriate competencies $(45.7 \%)$. However, it should be noted that the number of those who thought that the lack of managers with appropriate competencies was twice as higher than those who thought that a lack of integrated communication protocol represents a relatively bigger barrier (Figure 5c).

The majority of respondents (41\%) considered lack of financial resources a bigger issue than a lack of conscious planning (Figure 5d). The proportion of respondents who were indifferent and thought the opposite was quite similar (about $30 \%$ ).

The study also confirms that a limited availability of financial resources represent a bigger obstacle to the digital transformation of the examined companies compared to employees' resistance (Figure 5e). This conclusion was confirmed by the majority of surveyed managers (51.4\%).

When it comes to the lack of standards of technology and processes and resistance of the middle management, the number of those who thought that the lack of standards (technology and process) is more significant barrier compared to the middle management resistance was 50\% higher than those who thought the opposite (Figure $5 \mathrm{f}$ ).

The study reveals that indifference also exists when it comes to the following barriers of Industry 4.0: lack of abilities within the company vs. inadequate organizational structure (52.9\%), lack of conscious definition of goals and resources vs. inadequate process organization (61.4\%), lack of management with appropriate competencies vs. lack of integrated communication protocol $(45.7 \%)$ and return and profitability vs. lack of appropriate common thinking (38.6\%) (for additionally mentioned barriers see Appendix B).

\subsection{The Value Chain Digitalization}

In order to take a deeper look into the stage of digital maturity of the observed enterprises, an activity-level analysis was also conducted. Namely, to meet the challenges that Industry 4.0 imposes, enterprises will need certain capabilities across the entire value chain. The authors tested the managers' opinions on how digitalized the activities (primary and support activities) in their enterprises were (in terms of Porter, 1985) [74] using a Likert scale.

Respondents' opinions regarding the use of digital technology to conduct primary value chain activities were first examined. The results show that digital technology was mostly used to support production activities (74.3\% of managers agreed or strongly agreed with this statement). The examined companies used digital technologies to support both inbound and outbound logistics $(61.4 \%)$, shape marketing and sales campaigns (61.4\%) and support service activities (60\%).

When it comes to the supporting activities, $74.3 \%$ of respondents agreed or strongly agreed that digital technology is being used to support infrastructure, and $60 \%$ of respondents agreed or strongly agreed that they use digital technology to support procurement as well as research and development. The lowest level of usage of digital technology was identified in the recruitment and selection of employees (47.1\%).

The highest degree of agreement regarding the digitalization issue is linked to the strategy, which is in line with the digital maturity model results. As many as $87.1 \%$ of respondents agreed or strongly agreed that the top management of their company truly supports the implementation of a digital strategy (see Figure 6). More than $80 \%$ of respondents claimed that their companies integrate digitalization into their business strategy. Finally, $79 \%$ of surveyed managers believed that intensive use of digitalization and automation would allow their company to increase their performance against competitors as well as increase their revenues. 


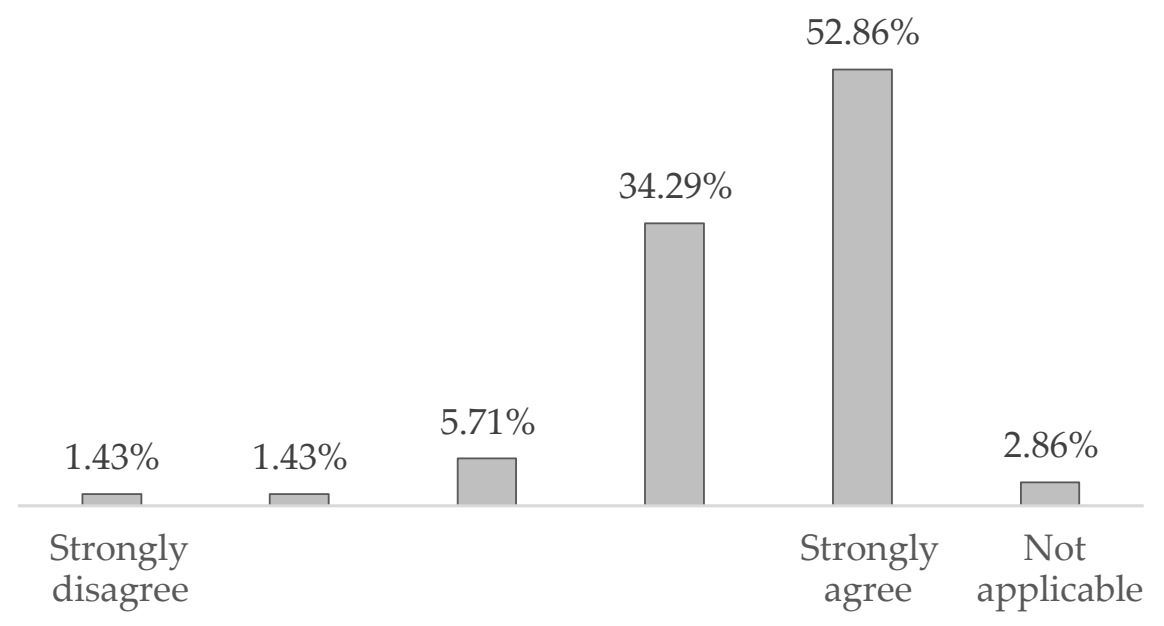

Figure 6. Respondents' rates of agreement with the statement "The management of our company truly supports the implementation of digital strategy".

Figures 7 and 8 portray the areas with the highest degree of agreement and disagreement.

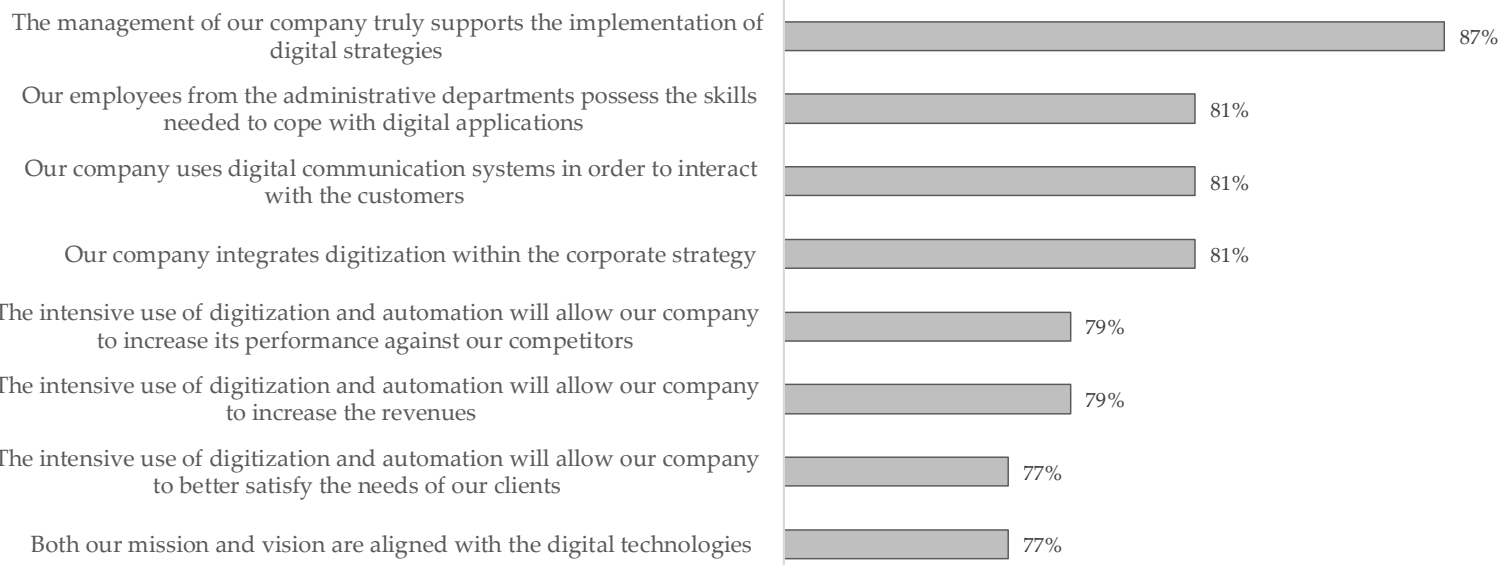

Figure 7. Statements with the highest degree of agreement (percentage of respondents who answered "agree" or "strongly agree").

The manipulation of both raw materials and finished products is done automatically

The activities within our warehouses are fully automated

The transport acitivities are planned with the help of digital technologies

Our company uses online bidding and negotiation

Our company uses e-procurement technologies

Our company uses digital technologies for recruiting and selecting personnel

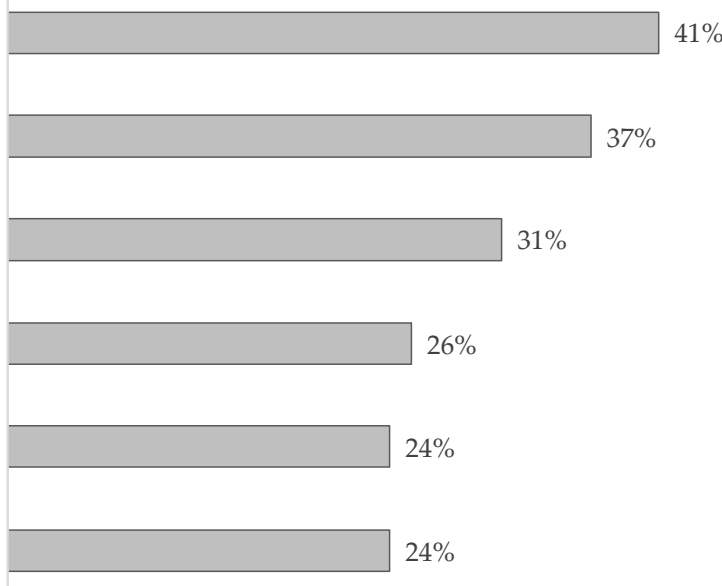

Figure 8. Statements with the highest degree of disagreement (percentage of respondents who answered "disagree" or "strongly disagree"). 


\subsection{Digital Transformation and Stakeholders Support}

The results of the study have clearly shown that government assistance and support in the digital transformation process is less important compared to other stakeholders. Precisely, about $60 \%$ of respondents considered government support important or very important, $18.5 \%$ considered it completely irrelevant or marginal, and the rest found it moderately important. Government support is first and foremost important regarding the financial issues in implementing Industry 4.0.

Support from the academic community was considered more important. The results have shown that $78.5 \%$ of respondents considered the support of universities and research institutes important or very important. Their support was most needed when it comes to the area of human resources and technical issues. If they needed to get the knowledge and education about Industry 4.0, most respondents would look for it at universities and research institutes $(37 \%)$, the Internet $(23 \%)$, and suppliers of Industry 4.0 ( $21 \%$ of respondents).

Undoubtedly the greatest importance, and therefore the greatest support in the process of conducting digital transformation, was needed by suppliers and users of Industry 4.0, as is easily noticed in Figure 9. The previous conclusion confirms the fact that $80 \%$ of respondents considered the support of Industry 4.0 suppliers as important or very important, and in the case of Industry 4.0 users as much as $85.7 \%$. Their support was primarily needed in the area of resolving technical issues.

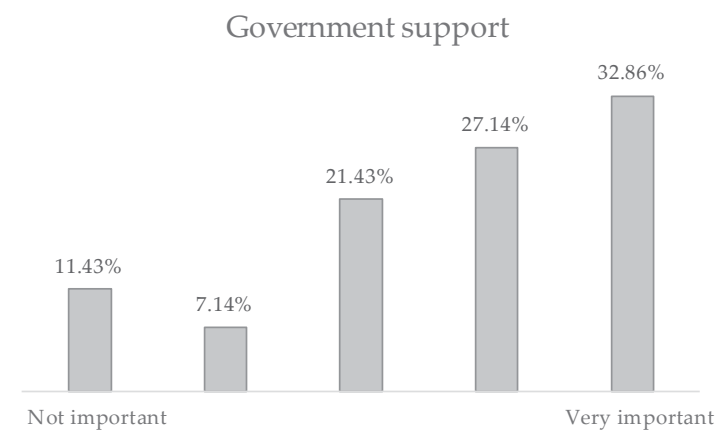

Users of Industry 4.0 support

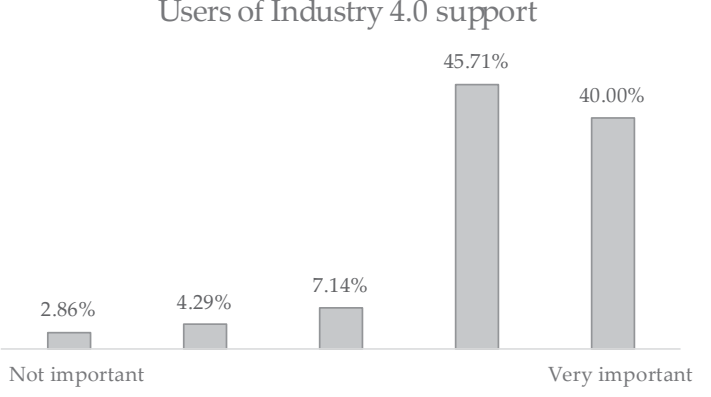

Universities and research institutes support

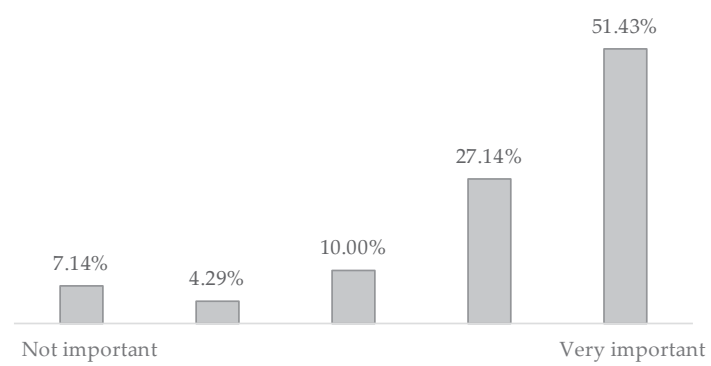

Suppliers of Industry 4.0 support

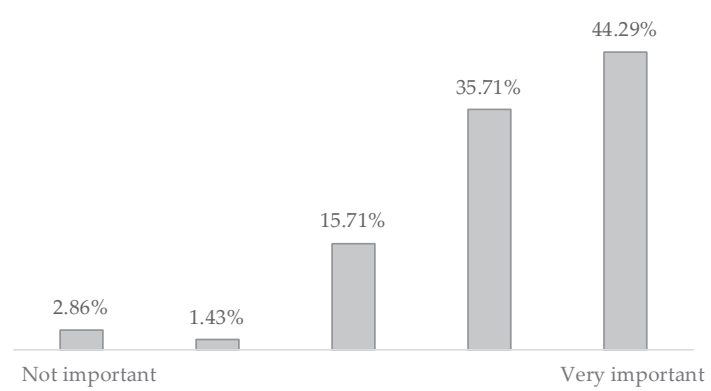

Figure 9. How important is the support of different actors of Industry 4.0 in the process of digital transformation?

\section{Discussion}

This research made an attempt to examine the main challenges and driving forces of the Industry 4.0 in a de-industrialized country's manufacturing sector.

In order to gain insight about Industry 4.0 in Serbia from the companies with the highest level of digital maturity, the level of digital transformation was first examined. Almost all companies from the sample (99\%) fell into categories of median and high digital maturity (42\% of sample companies were perceived at a median digital maturity level and $57 \%$ were perceived as highly digitally matured). The results are in favor of median and higher digital maturity companies due to 
the fact that already digitized companies showed a higher interest in completing the questionnaire compared to non-digitized enterprises.

Since the survey responses came mainly from the digitally matured manufacturing companies in Serbia (as perceived by their high level managers), the results of the test of digital maturity in Serbia are biased and it was not possible to draw conclusion about the achieved level of digital transformation within the country. Alternatively, it could be said that managers see manufacturing companies in Serbia as relatively more digitalized when compared to the results of digital maturity of companies in other small and medium middle-income developing countries

Deloitte's digital maturity model has general limitations similarly to other digital maturity models, stemming from its general and vague classification of companies in certain levels of digital maturity. Furthermore, digital maturity models suggest a linear path, suggesting that all companies follow the same path of digital transformation [20]. Finally, as with most of the maturity models, our chosen model is not academic even though it is based on empirical evidence. Yet, it was used as a basis for determining the reference points necessary to differentiate between Serbian companies in order to make the stratification of the sample and perform further analysis based on managers' opinions from relatively more matured companies.

Regarding the first hypothesis based on relevant literature [75-77] (Human-related factors represent a significant driving force and challenge for the Industry 4.0 enterprises), the research confirmed that digitally transforming companies in Serbia do not see human resources as a driving force but rather as an obstacle to Industry 4.0 implementation when they lack necessary competences and skills. Ganschar et al. [78] show that, apart from influencing workforce reduction, digital transformation leads to more complex tasks and processes and thus the skilled and educated employees represents an important prerequisite for the success of this process, which is confirmed in this research.

Regarding the second hypothesis based on relevant literature [3,5,54,60,63,79-82] (Achieving competitive advantage is a major driver of the Industry 4.0) empirical results in Serbia unexpectedly revealed that this driving force has been pushed into the background due to the relatively higher perceived importance of internal efficiency drivers (cost and time reduction).

When it comes to the barriers to Industry 4.0 implementation, there is a high degree of consistency among the responses. Hence, the barriers could be ranked according to their relative importance as presented in Figure 10.

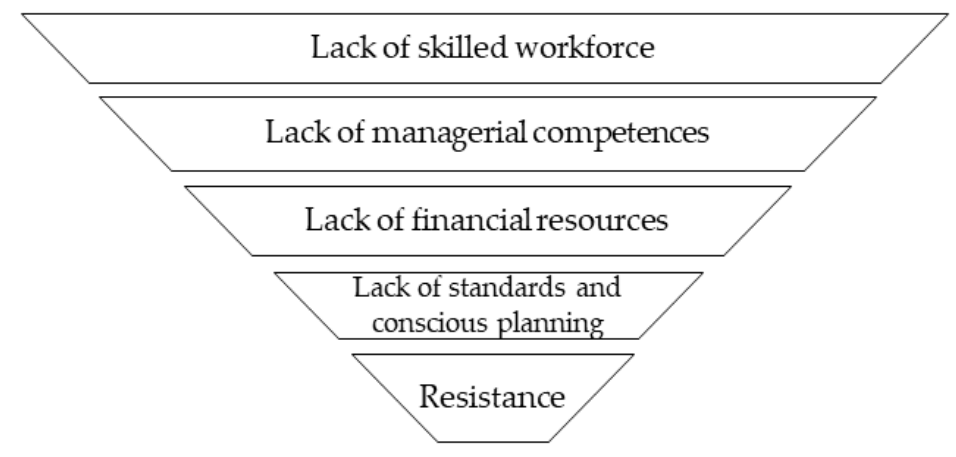

Figure 10. The biggest barriers to Industry 4.0.

The research results confirmed the third hypothesis (High cost of financing represent a major barrier to Industry 4.0 implementation in Serbia). A higher rank given to lacking financial resources can be prescribed to an underdeveloped financial market and the high cost of debt in Serbia.

Contrary to the literature [83-86], resistance to change caused by Industry 4.0 implementation was not seen as an important barrier among surveyed managers. Hence, the fourth hypothesis (Resistance to change creates pressure against Industry 4.0 implementation) has also not been confirmed. This could be explained by a relatively low level of economic activity in Serbia and consequent higher unemployment rate. Segal [86] also points to the existence of countries where workers' jobs are at a high risk, which is 
becoming even higher due to digitalization. The labor force is not mobile since Serbia is not a member of the EU, and thus losing existing jobs represents a significant threat to employees. Hence, employers and managers do not see them as a barrier.

According to Schumacher et al. [22] (p. 161), in the production technology area, the main impact of Industry 4.0 could be seen as increasing efficiency regarding manufacturing processes. Since the production technology is a dimension across which Serbian enterprises from the sample show the highest level of digital maturity, it is easy to explain why efficiency factors represent the main driving force.

\section{Conclusions}

In this paper, the authors conducted an analysis of the level of digital transformation of manufacturing enterprises in Serbia and examined their managers' opinions on the most important driving forces and implementation barriers to Industry 4.0 implementation.

Challenges and driving forces for Industry 4.0 differ when conducting a research in a de-industrialized, former socialist country compared to the majority of literature findings. Contrary to expectations, digitally transforming companies in Serbia do not see human resources as a driving force, but rather as an obstacle to Industry 4.0 implementation when they lack necessary competences and skills. Resistance to change caused by Industry 4.0 implementation is not seen as an important barrier. These findings indicate that even though managers with appropriate competences are necessary to succeed in the age of Industry 4.0, resistance within the organization hardly poses a threat. On the other hand, efficiency factors represent the main driving force, while the lack of financial resources along with inadequate and insufficient competences represent the greatest barriers to Industry 4.0 implementation. Similar to human resources, it is interesting to see that financial effects (profitability) are not seen as drivers of Industry 4.0. Rather, customer satisfaction is perceived as a significant driver of Industry 4.0. This can be interpreted as a demonstration of a responsible strategy where value creation for customers precedes value release for company owners. A hypothesis that digitally maturing companies implementing Industry 4.0 exhibit higher responsibility, taking care of sustainable value growth for both owners and consumers, can be an interesting start for future research.

According to the sample companies, the suppliers and users of Industry 4.0 are considered as the most important actors, with universities and research institutes following behind. This is in accordance with the results in the first part of the survey (Industry 4.0 interpretation, driving forces and barriers), showing that most of the Industry 4.0 is predominantly a consequence of customers' or partners' demands and requirements compared to employees' requirements. The majority of sample companies sought financial support from the government, whereas universities, the users and the suppliers of Industry 4.0 should provide help regarding technological issues according to the research. Papers tackling the opportunities and challenges that are considered relevant for the implementation of Industry 4.0 for companies are scarce. In response to the research gap in the field, this paper contributes to the current knowledge base with deeper insight into driving forces and barriers of Industry 4.0 implementation in a specific, context-related framework. Furthermore, the sample size in these papers is usually small, with a few exceptions (e.g., $[87,88]$ ). The authors, therefore, believe that this study fills a critical gap in the academic research in this field. Nevertheless, the research has its limitations, which need to be mentioned. The conducted type of exploratory research bears inherent limitations since it is based on human perception. However, at this level of Industry 4.0 implementation, hard data lacked for conducting an unbiased quantitative analysis. The authors attempted to overcome this limitation by surveying the companies that achieved the highest level of digital maturity in Serbia and thus possess the most valuable and the deepest experience with the Industry 4.0, which enhances the findings' reliability. 
For other researchers, the findings can be used as a basis for benchmark analyses in countries that share similarities with Serbia. Moreover, in order to enhance the representativeness of the findings, a quantitative cross-country empirical analysis is a recommended avenue of future research.

Furthermore, it is not guaranteed that our list of potential driving forces and barriers is exhaustive. The survey was based on the thorough literature analysis of the Industry 4.0 driving forces and barriers but cannot exclude the presence of other significant driving forces and barriers not mentioned in the survey. For example, the open innovation perspective of Industry 4.0 [10] suggests that "knowledge and experience within an organization are necessarily limited and that internal regulations and processes may even represent further limitations to innovation" and thus are a limitation to boosting the full potentials of Industry 4.0. In this respect, the authors acknowledge that there could be important dynamic capabilities and know-how determinants not included in the study. Hence, the validity of the conclusions is potentially limited by the bias caused by the exclusion of these factors. Additionally, further analysis of the driving forces and barriers could include more precise measurement of the importance of each factor.

Author Contributions: Conceptualization, I.V.H. and V.K.; methodology, I.V.H., V.K., T.H.; formal analysis, I.V.H., V.K. and V.M.M.; investigation, V.K.; resources, I.V.H., T.H. and V.M.M.; data curation, V.K.; writing-original draft preparation, I.V.H.; writing-review and editing, V.K., V.M.M. and T.H.; visualization, V.M.M. and V.K.; supervision, I.V.H. All authors have read and agreed to the published version of the manuscript.

Funding: This research received no external funding.

Conflicts of Interest: The authors declare no conflict of interest. 


\section{Appendix A. Additional Driving Forces of Industry 4.0}

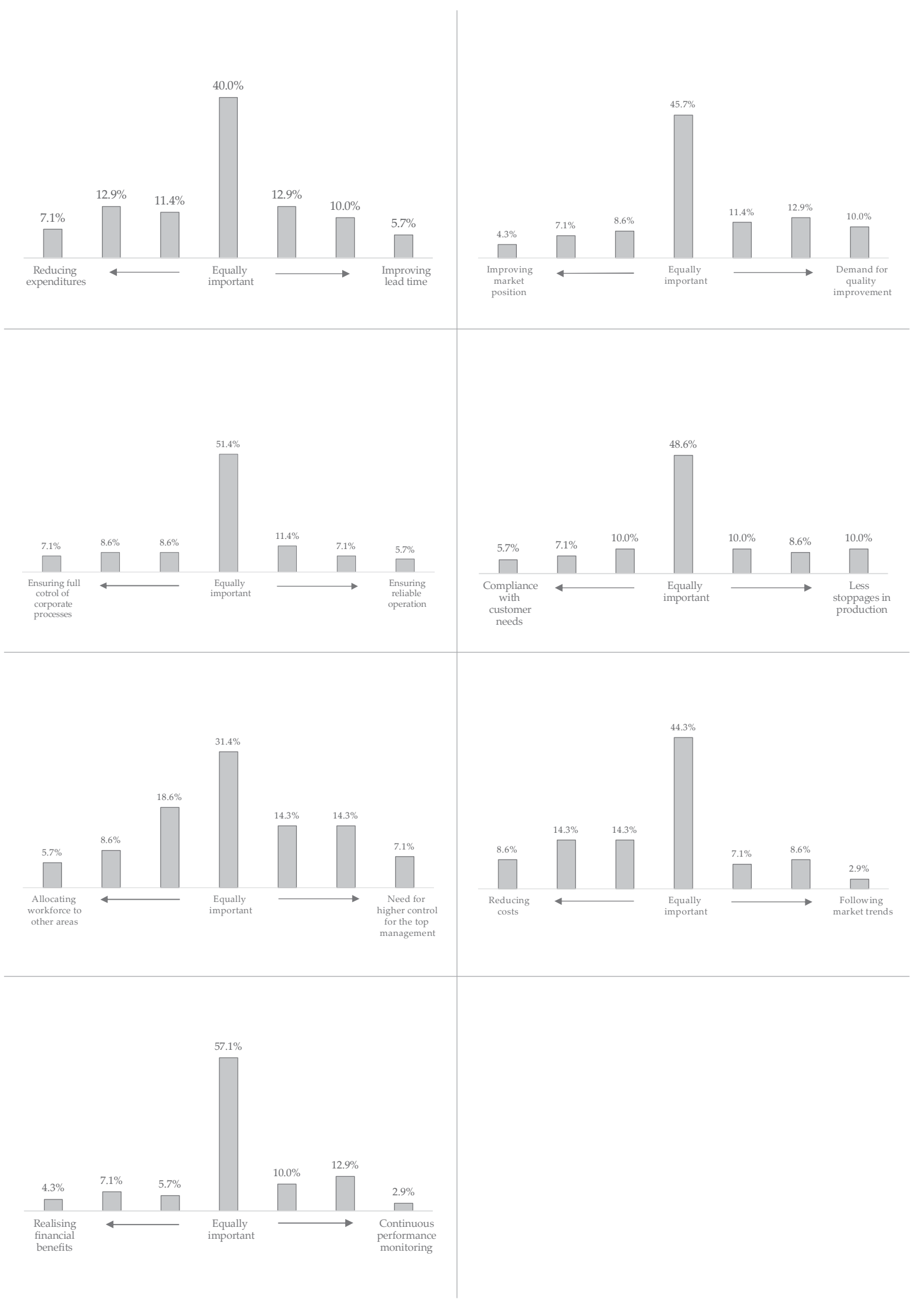

Figure A1. Additional driving forces of Industry 4.0. 


\section{Appendix B. Additional Barriers to Industry 4.0}

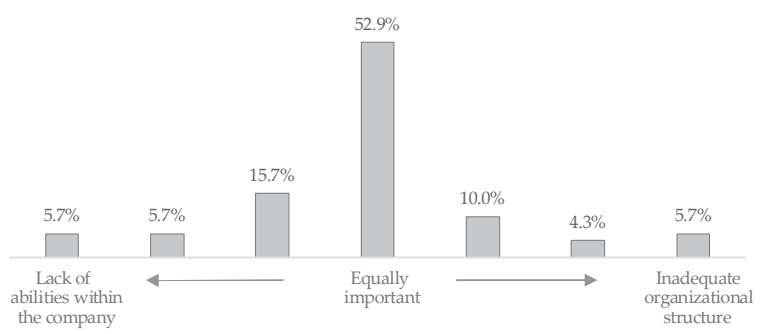

a)

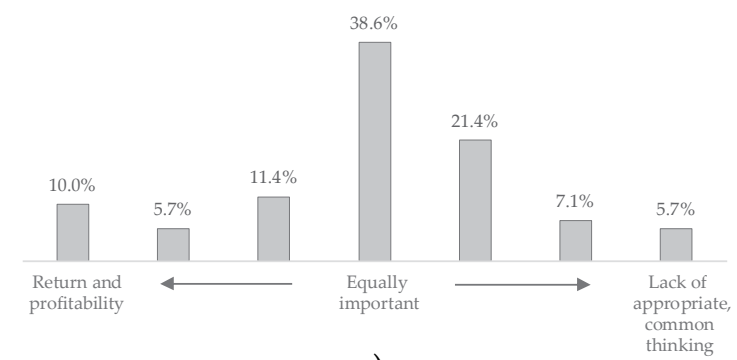

c)

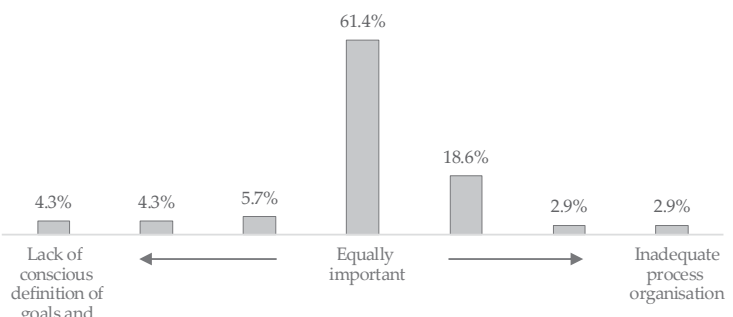

b)

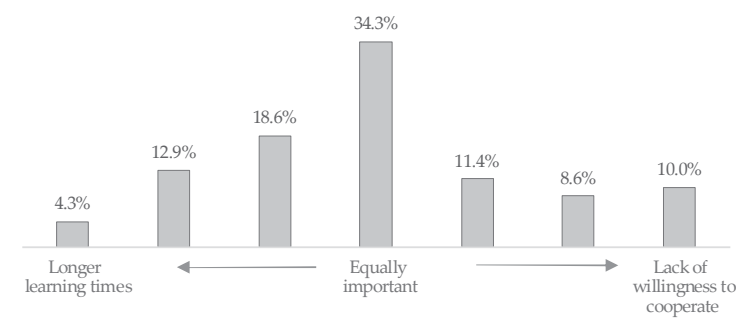

d)

Figure A2. Additional barriers to Industry 4.0.

\section{References}

1. Stock, T.; Obernaus, M.; Kunz, S.; Khol, H. Industry 4.0 as an enabler for sustainable development: A qualitative assessment of its ecological and social potential. Process Saf. Environ. Prot. 2018, 118, $254-267$. [CrossRef]

2. Saxena, P.; Papanikolaou, M.; Pagone, E.; Salonitis, K.; Jolly, R. Digital manufacturing for foundries 4.0. In Light Metal 2020-The Minerals, Metals \& Materials Series; Tomsett, A., Ed.; Springer: Berlin/Heidelberg, Germany, 2020; pp. 1019-1031.

3. Stock, T.; Seliger, G. Opportunities of sustainable manufacturing in industry 4.0. Procedia Cirp 2016, 40, 536-541. [CrossRef]

4. Fitzgerald, M.; Kruschwitz, N.; Bonnet, D.; Welch, M. Embracing digital technology: A new strategic imperative. MIT Sloan Manag. Rev. 2014, 55, 1-12.

5. Lasi, H.; Fettke, P.; Kemper, H.G.; Feld, T.; Hoffmann, M. Industry 4.0. Bus. Inform. Syst. Eng. 2014, 6, 239-242. [CrossRef]

6. McDonald, M.P.; Rowsell-Jones, A. The Digital Age: Exploiting Information E Technology for Business Advantage; Gartner: Stamford, CT, USA, 2012; ISBN 9780988389717.

7. Bleicher, J.; Stanley, H. Digitalization as a catalyst for business model innovation: A three step approach to facilitating economic success. J. Bus. Manag. 2016, 12, 62-71.

8. Horváth, D.; Szabó, R.Z. Driving forces and barriers of Industry 4.0: Do multinational and small and medium-sized companies have equal opportunities? Technol. Forecast. Soc. Chang. 2019, 146, 119-132. [CrossRef]

9. Chesbrough, H.; Appleyard, M. Open innovation and strategy. Calif. Manag. Rev. 2007, 50, 57-76. [CrossRef]

10. Travaglioni, M.; Ferazzoli, A.; Petrillo, A.; Cioffi, R.; De Felice, F.; Piscitelli, G. Digital manufacturing challenges through open innovation perspective. Procedia Manuf. 2020, 42, 165-172. [CrossRef]

11. Kagermann, H.; Lukas, W.D.; Wahlster, W. Industrie 4.0: Mit dem Internet der Dinge auf dem Weg zur 4. industriellen Revolution. VDI Nachr. 2011, 13, 1-2.

12. Arnold, C.; Kiel, D.; Voigt, K.I. How the industrial internet of things changes business models in different manufacturing industries. Int. J. Innovat. Manag. 2016, 20, 1640015. [CrossRef] 
13. Muller, J.; Dotzauer, V.; Voigt, K.I. Industry 4.0 and its impact on reshoring decisions of German manufacturing enterprises. In Supply Management Research-Advanced Studies in Supply Management, 1st ed.; Bode, C., Bogasczevsky, R., Eßig, M., Lash, R., Stölzle, W., Eds.; Springer: Berlin/Heidelberg, Germany, 2017; Volume 1, pp. 165-179.

14. Matt, C.; Hess, T.; Benlian, A. Digital transformation strategies. Bus. Inform. Syst. Eng. 2015, 57, 339-343. [CrossRef]

15. Industry 4.0 How to Navigate Digitization of the Manufacturing Sector. Available online: https://www.mckinsey.com/ \{\}/media/McKinsey/Business\%20Functions/Operations/Our\%20Insights/ Industry\%2040\%20How\%20to\%20navigate\%20digitization\%20of\%20the\%20manufacturing\%20sector/ Industry-40-How-to-navigate-digitization-of-the-manufacturing-sector.ashx (accessed on 5 April 2020).

16. Basl, J. Pilot study of readiness of Czech companies to implement the principles of Industry 4.0. Manag. Prod. Eng. Rev. 2017, 8, 3-8. [CrossRef]

17. Müller, J.M.; Buliga, O.; Voigt, K.I. Fortune favors the prepared: How SMEs approach business model innovations in Industry 4.0. Technol. Forecast. Soc. Chang. 2018, 132, 2-17. [CrossRef]

18. Bonilla, S.H.; Silva, H.R.; Terra da Silva, M.; Franco Gonçalves, R.; Sacomano, J.B. Industry 4.0 and sustainability implications: A scenario-based analysis of the impacts and challenges. Sustainability 2018, 10, 3740. [CrossRef]

19. Kane, G.C.; Palmer, D.; Nguyen-Phillips, A.; Kiron, D.; Buckley, N. Achieving digital maturity. MIT Sloan Manag. Rev. 2017, 59, 1-11.

20. Digital Maturity in Traditional Industries-An Exploratory Analysis. Available online: https://pdfs. semanticscholar.org/8296/848850c729e70e4dac01198db7b8ae410f99.pdf (accessed on 5 April 2020).

21. Proença, D.; Borbinha, J. Maturity models for information systems-A state of the art. Procedia Comput. Sci. 2016, 100, 1042-1049. [CrossRef]

22. Schumacher, A.; Erol, S.; Sihn, W. A maturity model for assessing Industry 4.0 readiness and maturity of manufacturing enterprises. Procedia Cirp 2016, 52, 161-166. [CrossRef]

23. Tarhan, A.; Turetken, O.; Reijers, H.A. Business process maturity models: A systematic literature review. Inf. Softw. Technol. 2016, 75, 122-134. [CrossRef]

24. Chanias, S.; Hess, T. How digital are we? Maturity models for the assessment of a company's status in the digital transformation. Manag. Rep. Inst. Wirtsch. Neue Medien 2016, 2, 1-14.

25. What Does 'Digital Transformation' Really Mmean? Available online: https://www.marketingweek.com/ what-does-digital-transformation-really-mean/ (accessed on 5 April 2020).

26. Seufert, S.; Meier, C. From eLearning to digital transformation: A framework and implications for L\&D. Int. J. Corp. Learn. 2016, 9, 27-33. [CrossRef]

27. Shewhart, W. Economic Control of Quality of Manufactured Product; Van Nostrand: New York, NY, USA, 1931.

28. Deming, W. Out of the Crisis; MIT-Press: Cambridge, MA, USA, 1986.

29. Crosby, P. Quality Is Free: The Art of Making Quality Certain; McGraw-Hill: New York, NY, USA, 1979.

30. Juran, J. Juran on Planning for Quality; The Free Press: New York, NY, USA, 1988.

31. Humphrey, W. Managing the Software Process; Addison-Wesley: Reading, MA, USA, 1989.

32. Hüner, K.; Ofner, M.; Otto, B. Towards a maturity model for corporate data quality management. In Proceedings of the 2009 ACM Symposium on Applied Computing, Honolulu, HI, USA, 9-12 March 2009; Association for Computing Machinery: New York, NY, USA, 2009; pp. 231-238.

33. European Foundation for the Quality Management. Introducing Excellence; European Foundation for the Quality Management: Brussels, Belgium, 2003.

34. Industry 4.0: Building the Digital Enterprise. Available online: https://www.pwc.com/gx/en/industries/ industrial-manufacturing/publications/assets/pwc-building-digital-enterprise.pdf (accessed on 5 April 2020).

35. Digitalisierung im Mittelstand. Available online: http://www.forschungsnetzwerk.at/downloadpub/ Digitalisierung-im-Mittelstand.pdf (accessed on 5 April 2020).

36. Digital Maturity Model: Achieving Digital Maturity to Drive Growth. Available online: https: //www2.deloitte.com/content/dam/Deloitte/global/Documents/Technology-Media-Telecommunications/ deloitte-digital-maturity-model.pdf (accessed on 5 April 2020).

37. The Digital Advantage: How Digital Leaders Outperform Their Peers in Every Industry. Available online: https://www.capgemini.com/wp-content/uploads/2017/07/The_Digital_Advantage_How_Digital_ Leaders_Outperform_their_Peers_in_Every_Industry.pdf (accessed on 5 April 2020). 
38. Digital Maturity \& Transformation Report 2016. Available online: https://www.digitaleschweiz.ch/wpcontent/uploads/2016/06/digital-maturity-transformation-report-2016-mit-best-practices.pdf (accessed on 5 April 2020).

39. Berghaus, S.; Back, A. Stages in Digital Business Transformation: Results of an Empirical Maturity Study. In Proceedings of the Tenth Mediterranean Conference on Information Systems (MCIS), Paphos, Cyprus, 4-6 September 2016.

40. Impuls: Industrie 4.0 Readiness. Available online: https://industrie40.vdma.org/documents/4214230/ 26342484/Industrie_40_Readiness_Study_1529498007918.pdf/0b5fd521-9ee2-2de0-f377-93bdd01ed1c8 (accessed on 5 April 2020).

41. Lanza, G.; Nyhuis, P.; Ansari, S.M.; Kuprat, T.; Liebrecht, C. Empowerment and implementation strategies for Industry 4.0. ZWF Z. Wirtsch. Fabr. 2016, 111, 76-79. [CrossRef]

42. Savastano, M.; Amendola, C.; Bellini, F.; D'Ascenzo, F. Contextual impacts on industrial processes brought by the digital transformation of manufacturing: A systematic review. Sustainability 2019, 11, 891. [CrossRef]

43. Shah, R.; Ward, P. Defining and developing measures of lean production. J. Oper. Manag. 2007, 25, 785-805. [CrossRef]

44. Tortorella, G.; Cawley Vergara, A.; Mac Garza-Reyes, J.; Sawhney, R. Organizational learning paths based upon industry 4.0 adoption: An empirical study with Brazilian manufacturers. Int. J. Prod. Econ. 2020, 284-294. [CrossRef]

45. Industry 4.0: The Future of Productivity and Growth in Manufacturing Industries. Available online: https://www.bcg.com/publications/2015/engineered_products_project_business_industry_4_future_ productivity_growth_manufacturing_industries.aspx (accessed on 5 April 2020).

46. Burmeister, C.; Lüttgens, D.; Piller, F.T. Business model innovation for Industrie 4.0: Why the "Industrial Internet" mandates a new perspective on innovation. Die Unternehm. 2016, 70, 124-152. [CrossRef]

47. Arnold, C.; Veile, J.; Voigt, K.I. What Drives Industry 4.0 Adoption? An Examination of Technological, Organizational, and Environmental Determinants. In Proceedings of the International Association for Management of Technology (IAMOT) Conference, Birmingham, UK, 22-26 April 2018.

48. Laudien, S.M.; Daxböck, B. Business model innovation processes of average market players: A qualitativeempirical analysis. $R$ D Manag. 2017, 47, 420-430. [CrossRef]

49. Laudien, S.M.; Bouncken, R.; Pesch, R. Understanding the acceptance of digitalization-based business models: A qualitative-empirical analysis. Acad. Manag. Glob. Proc. 2018, 2018, 104.

50. Ibarra, D.; Ganzarain, J.; Igartua, J.I. Business model innovation through Industry 4.0: A review. Procedia Manuf. 2018, 22, 4-10. [CrossRef]

51. Ślusarczyk, B. Industry 4.0: Are we ready? Pol. J. Manag. Stud. 2018, 17, 232-248. [CrossRef]

52. Intelligent Efficiency: Opportunities, Barriers and Solutions. Available online: https://www.aceee.org/sites/ default/files/publications/researchreports/e13j.pdf (accessed on 5 April 2020).

53. Benefits and Barriers of Smart Manufacturing. Available online: https://oaktrust.library.tamu.edu/handle/ 1969.1/152162 (accessed on 5 April 2020).

54. Brettel, M.; Friederichsen, N.; Keller, M.; Rosenberg, M. How virtualization, decentralization and network building change the manufacturing landscape: An Industry 4.0 Perspective. Int. J. Mech. Ind. Sci. Eng. 2014, 8, 37-44.

55. Schmidt, R.; Möhring, M.; Härting, R.C.; Reichstein, C.; Neumaier, P.; Jozinović, P. Industry 4.0-potentials for creating smart products: Empirical research results. In Proceedings of the International Conference on Business Information Systems, Poznan, Poland, 24-26 June 2015.

56. Erol, S.; Jäger, A.; Hold, P.; Ott, K.; Sihn, W. Tangible Industry 4.0: A scenario-based approach to learning for the future of production. Procedia CiRp 2016, 54, 13-18. [CrossRef]

57. Oettmeier, K.; Hofmann, E. Additive manufacturing technology adoption: An empirical analysis of general and supply chain-related determinants. J. Bus. Econ. 2017, 87, 97-124. [CrossRef]

58. Müller, J.M.; Kiel, D.; Voigt, K.I. What drives the implementation of Industry 4.0? The role of opportunities and challenges in the context of sustainability. Sustainability 2018, 10, 247. [CrossRef]

59. Bonekamp, L.; Sure, M. Consequences of Industry 4.0 on human labor and work organization. J. Bus. Med. Psychol. 2015, 6, 33-40.

60. Kiel, D.; Müller, J.M.; Arnold, C.; Voigt, K.I. Sustainable industrial value creation: Benefits and challenges of industry 4.0. Int. J. Innov. Manag. 2017, 21, 1740015. [CrossRef] 
61. Agolla, J.E. Human capital in the smart manufacturing and industry 4.0 revolution. Dig. Transf. Smart Manuf. 2018, 2, 41-58. [CrossRef]

62. Manufacturing Work of the Future: Industry 4.0. Available online: https://www.produktionsarbeit.de/ content/dam/produktionsarbeit/de/documents/Management_Summary.pdf (accessed on 5 April 2020).

63. Herrmann, C.; Schmidt, C.; Kurle, D.; Blume, S.; Thiede, S. Sustainability in manufacturing and factories of the future. Int. J. Precis. Eng. Manuf. Green Technol. 2014, 1, 283-292. [CrossRef]

64. Bauer, W.; Hämmerle, M.; Schlund, S.; Vocke, C. Transforming to a hyper-connected society and economytowards an Industry 4.0. Procedia Manuf. 2015, 3, 417-424. [CrossRef]

65. Erol, S.; Scumaher, A.; Sihn, W. Strategic guidance towards Industry 4.0-a three-stage process model. In Proceedings of the International Conference on Competitive Manufacturing 2016 (COMA'16), Stellenbosch, South Africa, 27-29 January 2016.

66. Nagy, J.; Oláh, J.; Erdei, E.; Máté, D.; Popp, J. The role and impact of industry 4.0 and the internet of things on the business strategy of the value chain-The case of Hungary. Sustainability 2018, 10, 3491. [CrossRef]

67. Garland, R. A comparison of three forms of the semantic differential. Mark. Bull. 1990, 1, 19-24.

68. SEI. Appraisal Requirements for CMMI, Version 1.2 (ARC, V1.2); Carnegie Mellon University: Pittsburgh, PA, USA, 2006.

69. Fraser, P.; Moultrie, J.; Gregory, M. The use of maturity models/grids as a tool in assessing product development capability. In Proceedings of the IEEE International Engineering Management Conference, Cambridge, UK, 6 August 2002; pp. 245-247.

70. Grinstein, A.; Goldman, A. Characterizing the technology firm: An exploratory study. Res. Policy 2006, 35, 121-143. [CrossRef]

71. Warner, K.; Wäger, M. Building dynamic capabilities for digital transformation: An ongoing process of strategic renewal. Long Range Plan. 2019, 52, 326-349. [CrossRef]

72. Strategy, Not Technology, Drives Digital Transformation. Available online: https:/www2.deloitte.com/content/ dam/Deloitte/fr/Documents/strategy/dup_strategy-not-technology-drives-digital-transformation.pdf (accessed on 5 April 2020).

73. Felin, T.; Foss, N.J.; Ployhart, R.E. The micro foundations movement in strategy and organization theory. Acad. Manag. Ann. 2015, 9, 575-632. [CrossRef]

74. Porter, M.E. Competitive Advantage: Creating and Sustaining Superior Performance; The Free Press: New York, NY, USA, 1985; pp. 22-34.

75. Kesting, P.; Song, L.J.; Qin, Z.; Krol, M. The role of employee participation in generating and commercializing innovations: Insights from Chinese high-tech firms. Int. J. Hum. Resour. Manag. 2016, 27, 1059-1081. [CrossRef]

76. Lukes, M.; Stephan, U. Measuring employee innovation: A review of existing scales and the development of the innovative behavior and innovation support inventories across cultures. Int. J. Entrep. Behav. Res. 2017, 23, 136-158. [CrossRef]

77. Liboni, L.B.; Cezarino, L.O.; Jabbour, C.J.C.; Oliveira, B.G.; Stefanelli, N.O. Smart industry and the pathways to HRM 4.0: Implications for SCM. Supply Chain Manag. 2019, 24, 124-146. [CrossRef]

78. Produktionsarbeit der Zukunft- Industrie 4.0. Available online: https://www.iao.fraunhofer.de/images/iaonews/produktionsarbeit-der-zukunft.pdf (accessed on 5 April 2020).

79. Zhou, K.; Liu, T.; Zhou, L. Industry 4.0: Towards future industrial opportunities and challenges. In Proceedings of the 12th International Conference on Fuzzy Systems and Knowledge Discovery (FSKD 2015), Zhangjiajie, China, 15-17 August 2015. [CrossRef]

80. Roblek, V.; Meško, M.; Krapež, A. A complex view of industry 4.0. Sage Open 2016, 6. [CrossRef]

81. Bahrin, M.A.K.; Othman, M.F.; Azli, N.N.; Talib, M.F. Industry 4.0: A review on industrial automation and robotics. J. Teknol. 2016, 78, 137-143.

82. Witkowski, K. Internet of things, big data, industry 4.0-innovative solutions in logistics and supply chains management. Procedia Eng. 2017, 182, 763-769. [CrossRef]

83. Schuh, G.; Potente, T.; Wesch-Potente, C.; Weber, A.R.; Prote, J.P. Collaboration Mechanisms to increase Productivity in the Context of Industrie 4.0. Procedia Cirp 2014, 19, 51-56. [CrossRef]

84. Gorecky, D.; Schmitt, M.; Loskyll, M.; Zühlke, D. Human-machine-interaction in the industry 4.0 era. In Proceedings of the 12th IEEE International Conference on Industrial Informatics (INDIN 2014), Porto Alegre, Brazil, 27-30 July 2014. [CrossRef] 
85. Hirsch-Kreinsen, H. Digitalization of industrial work: Development paths and prospects. J. Labour Mark. Res. 2016, 49, 1-14. [CrossRef]

86. Segal, M. How automation is changing work. Nature 2018, 563, 132-135. [CrossRef] [PubMed]

87. Bloching, B.; Leutiger, P.; Oltmanns, T.; Rossbach, C.; Schlick, T.; Remané, G.; Quick, P.; Shafranyuk, O. The Digital Transformation of Industry; Roland Berger Strategy Consultants und Bundesverband der Deutschen Industrie: München, Germany, 2015.

88. Remane, G.; Hanelt, A.; Wiesböck, F.; Kolbe, L. Digital maturity in traditional industries: An exploratory analysis. In Proceedings of the Twenty-Fifth European Conference on Information Systems (ECIS), Guimarães, Portugal, 5-10 June 2017.

(C) 2020 by the authors. Licensee MDPI, Basel, Switzerland. This article is an open access article distributed under the terms and conditions of the Creative Commons Attribution (CC BY) license (http://creativecommons.org/licenses/by/4.0/). 